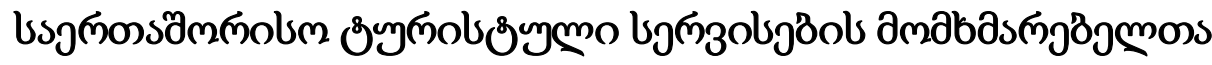

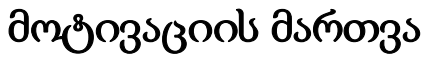

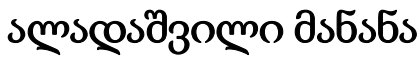

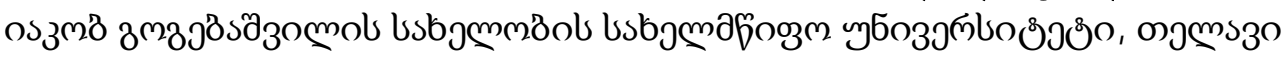

https://doi.org/10.52340/idw.2021.527

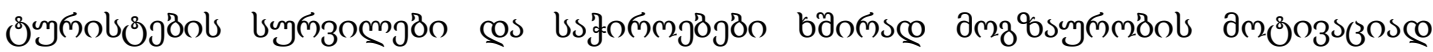

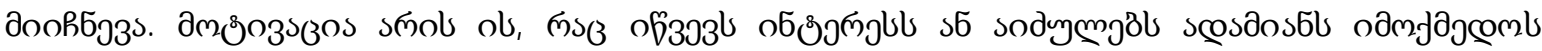

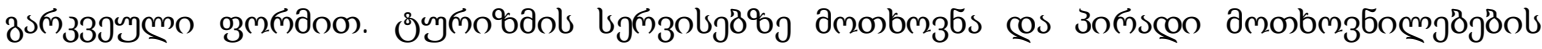

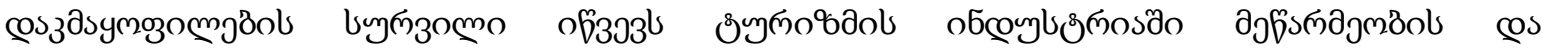

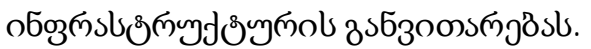

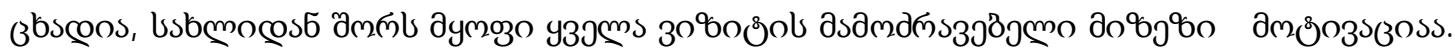

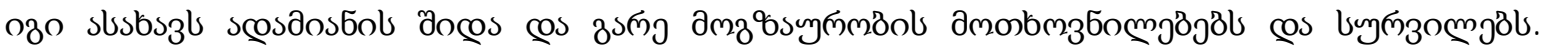

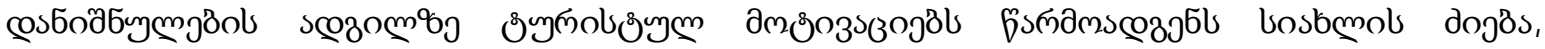

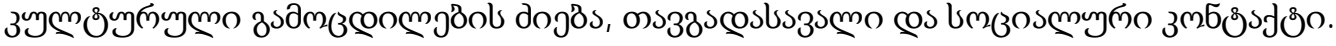

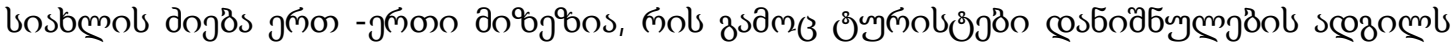

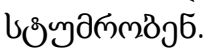

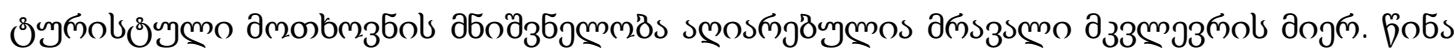

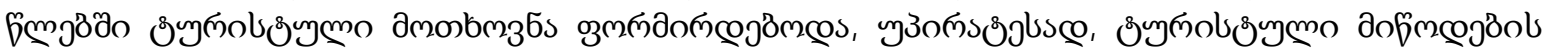

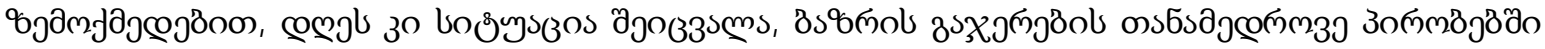

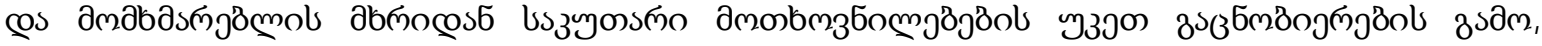

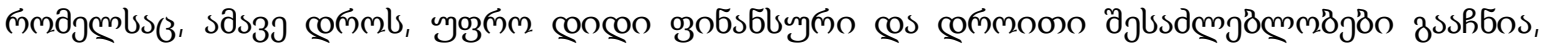

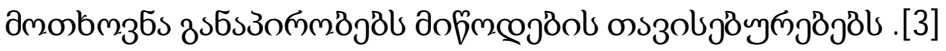

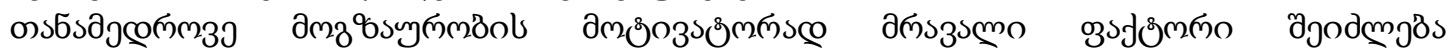

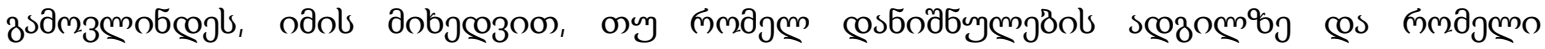

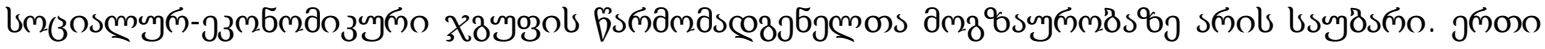

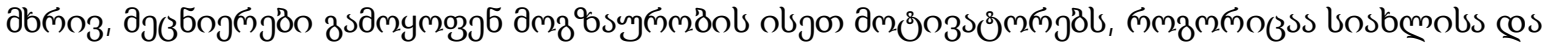

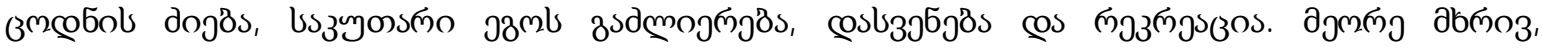

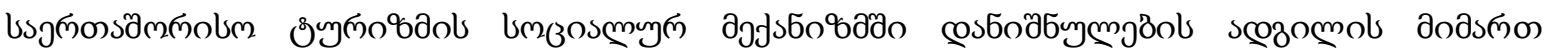

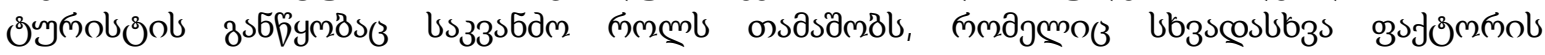

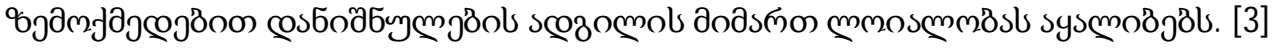

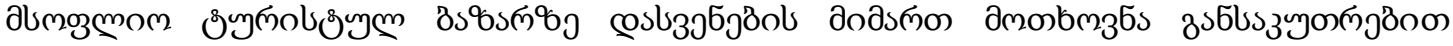

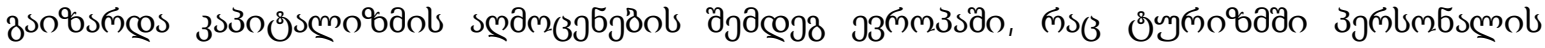

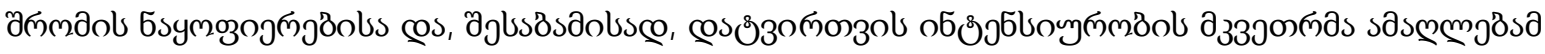

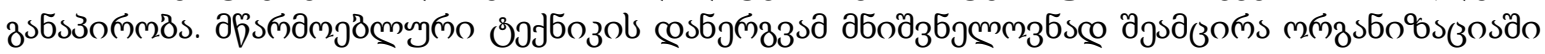

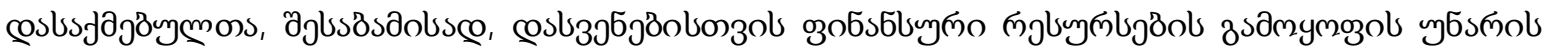

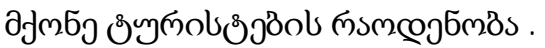

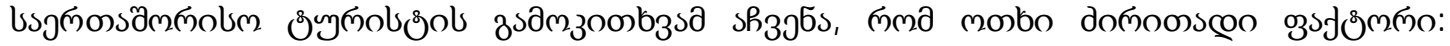

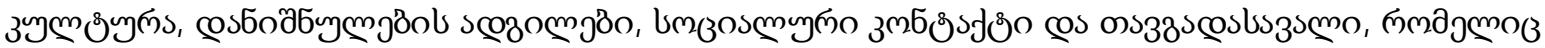

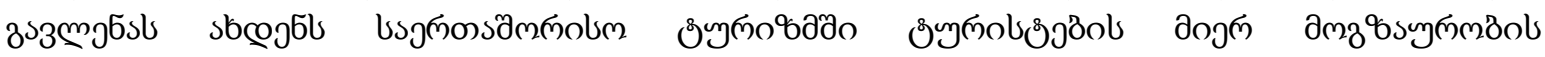




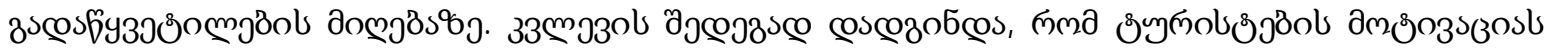

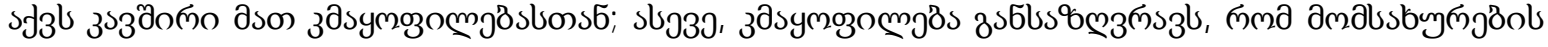

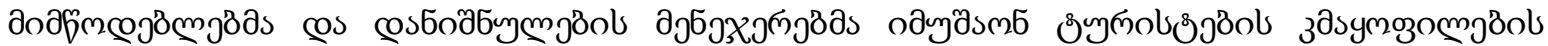

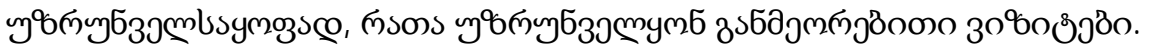

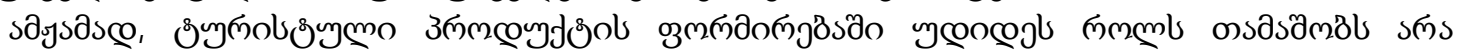

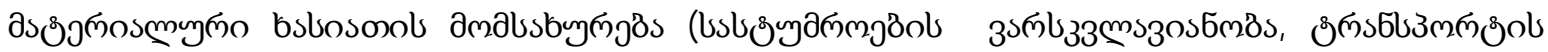

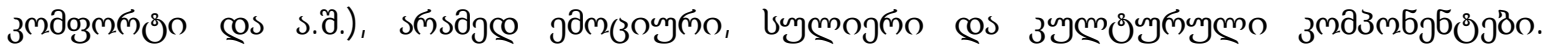

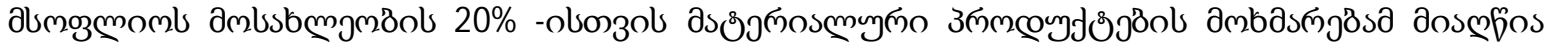

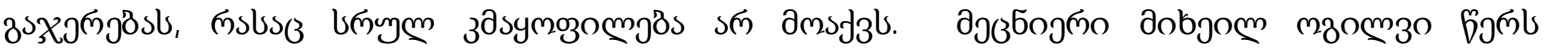

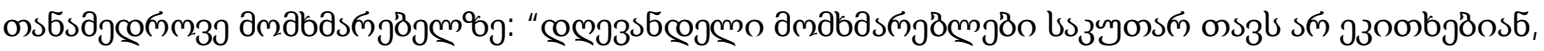

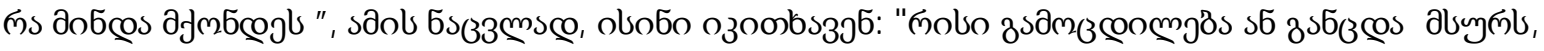

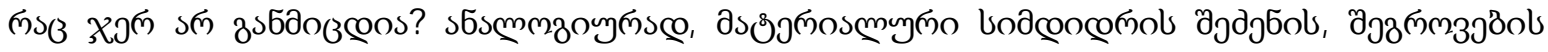

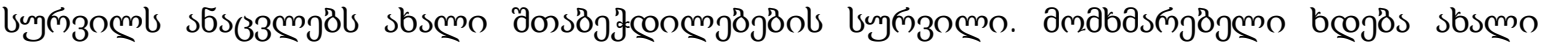

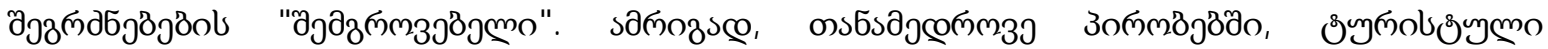

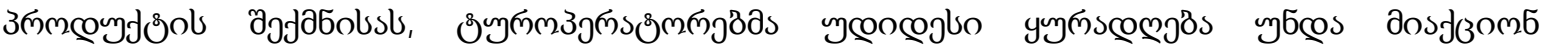

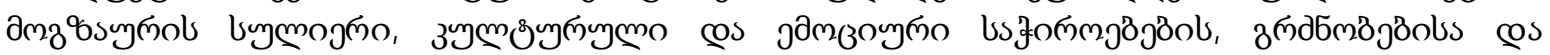

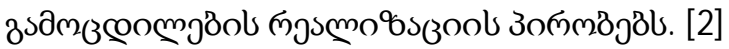

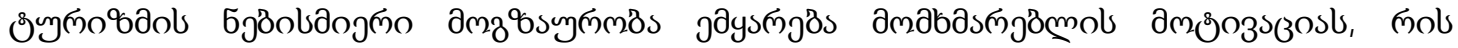

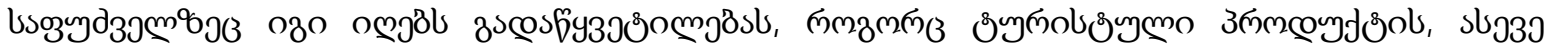

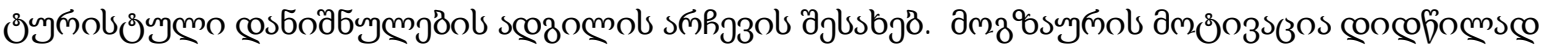

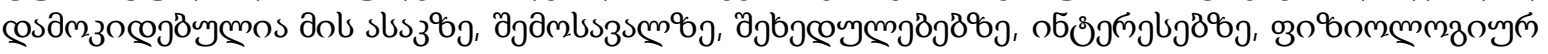

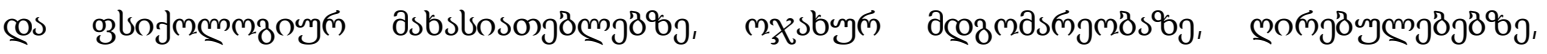
доœ约з

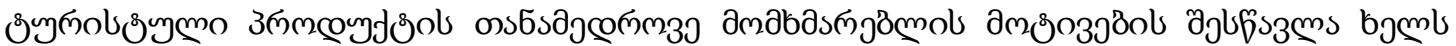

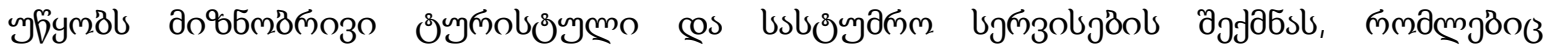

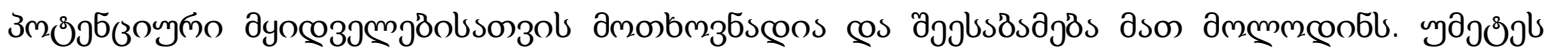

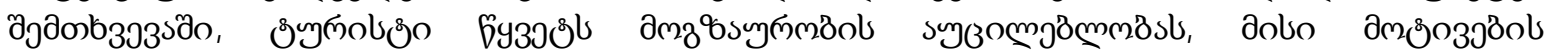

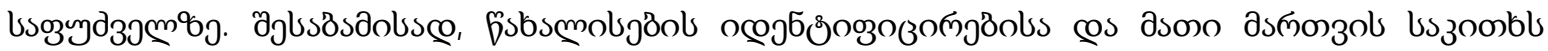

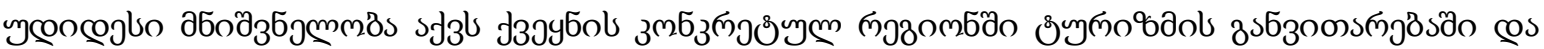

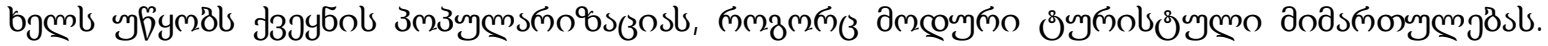

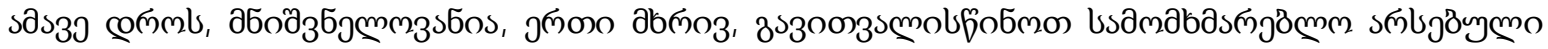

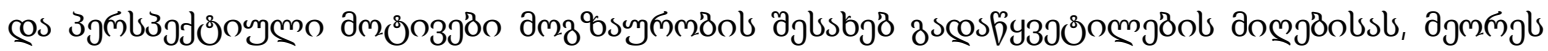

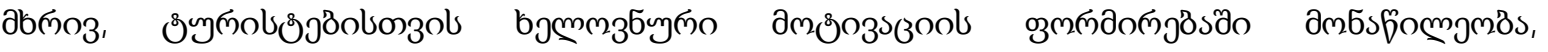

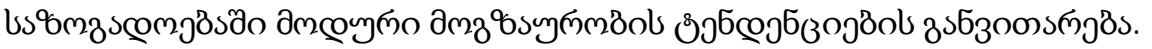

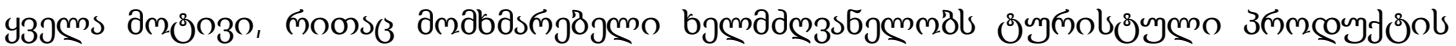

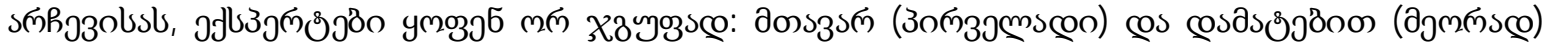

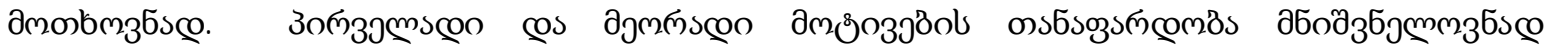

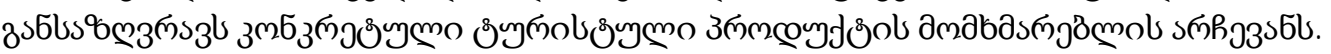

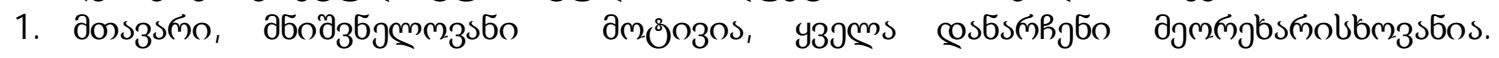

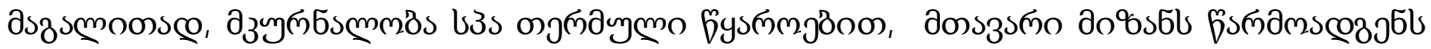

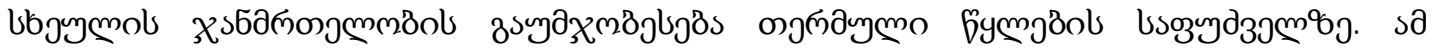

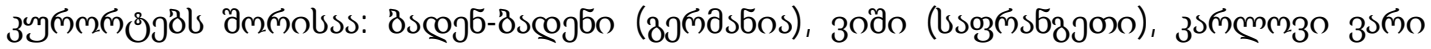

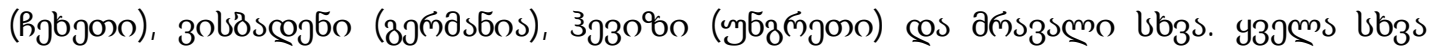

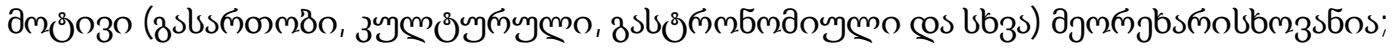

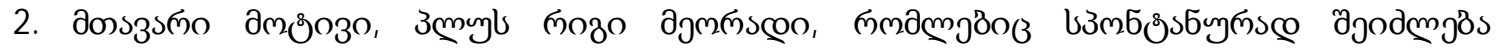

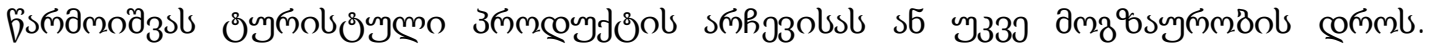

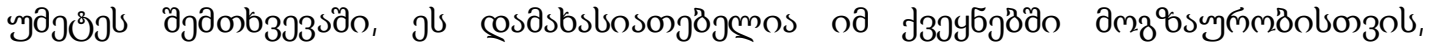

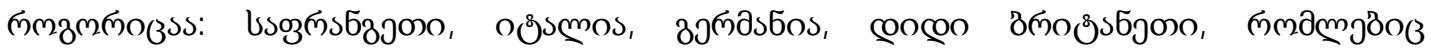

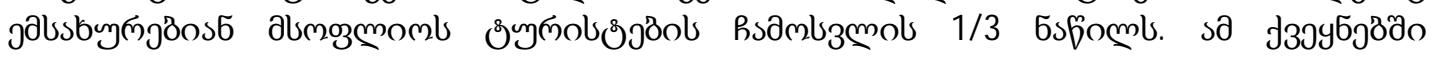




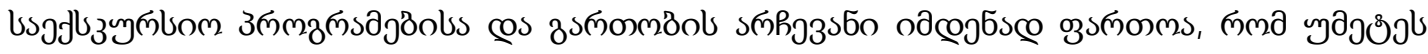

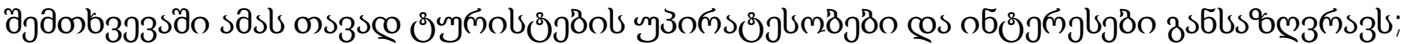

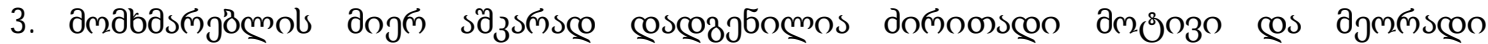

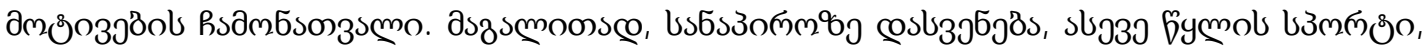

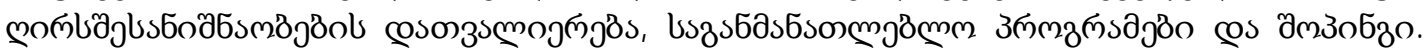

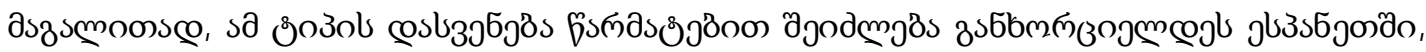
bsozms

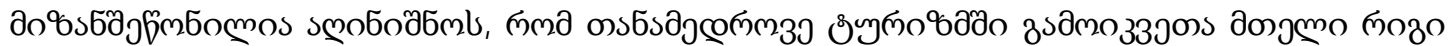

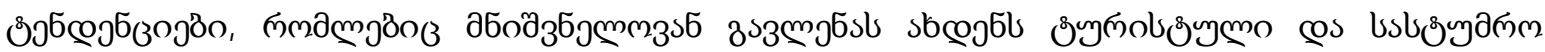

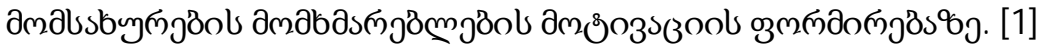

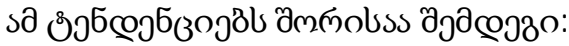

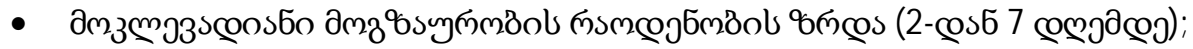

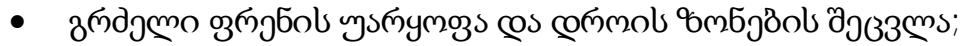

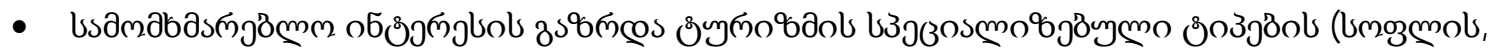

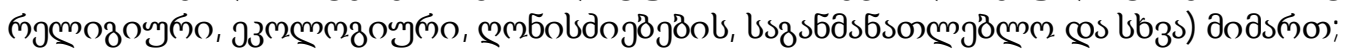

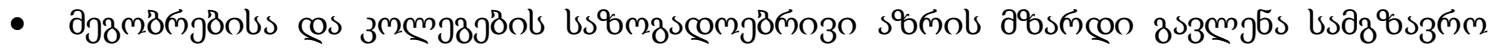

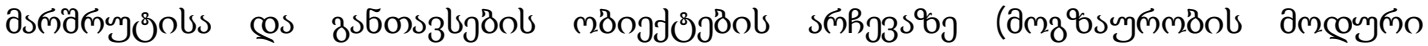

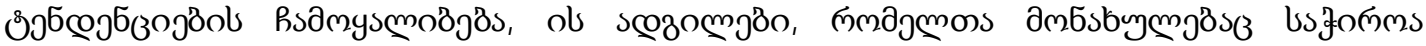

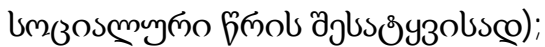

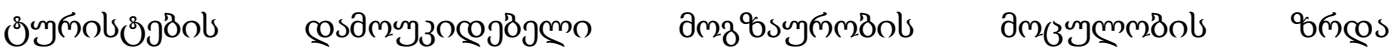

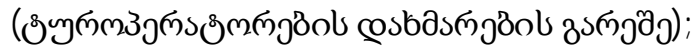

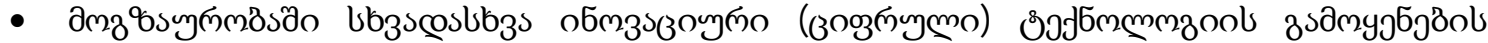

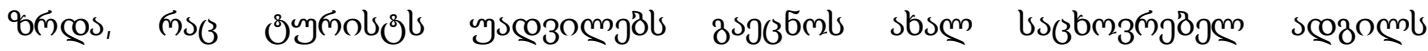

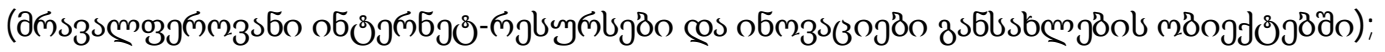

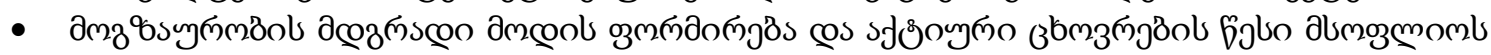

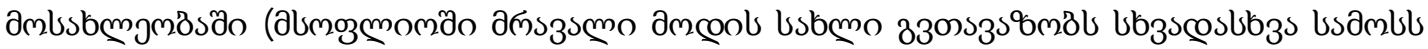
usamzissymmc).

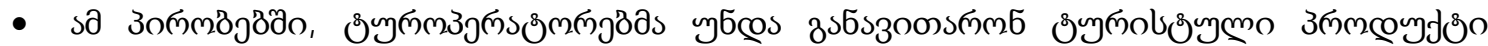

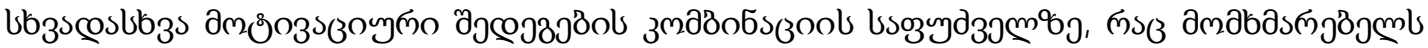

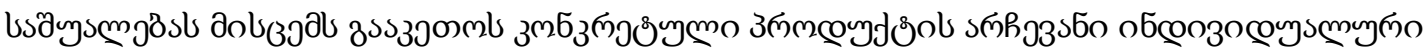

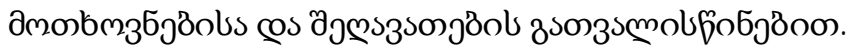

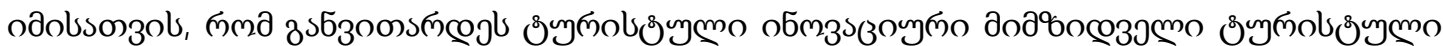

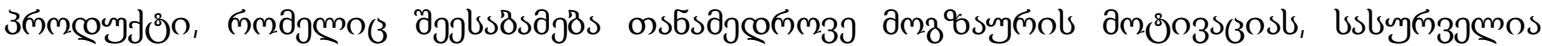

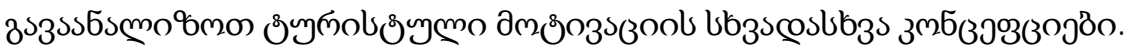

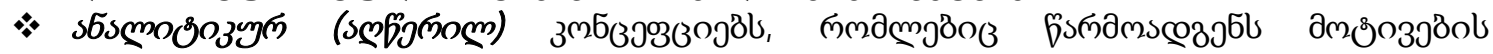

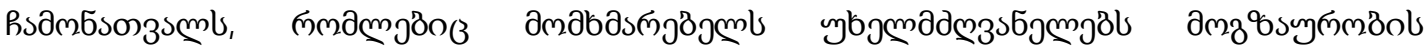

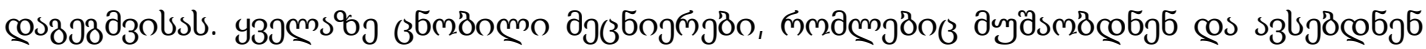

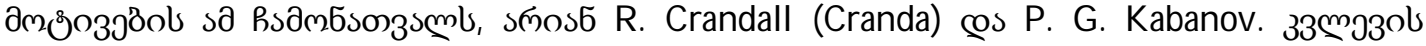

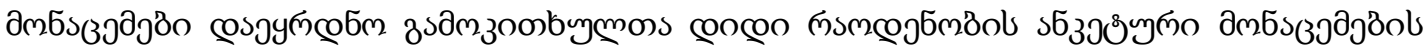

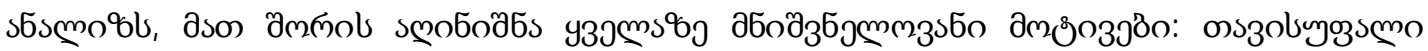

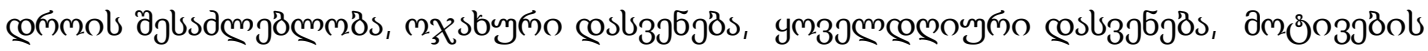

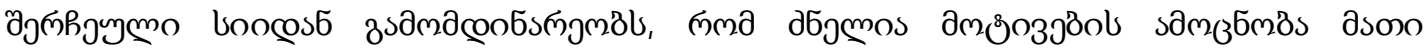

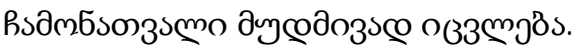

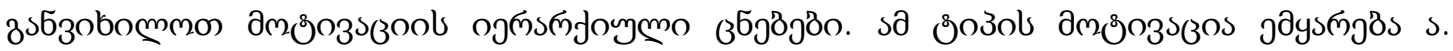

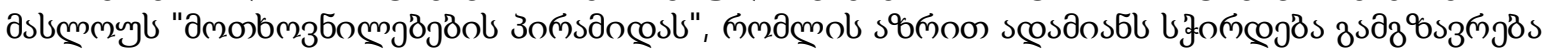

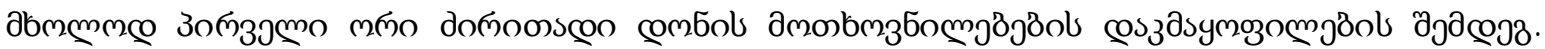

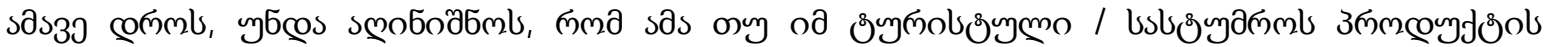

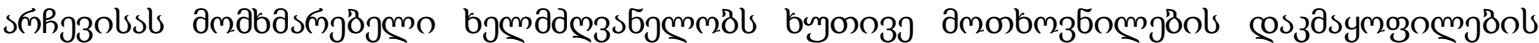


зизомудеммд̈оп.

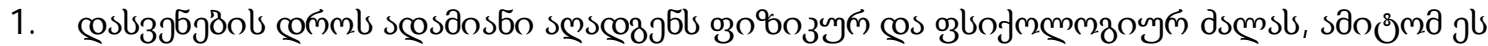

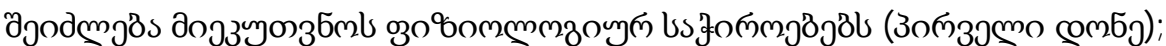

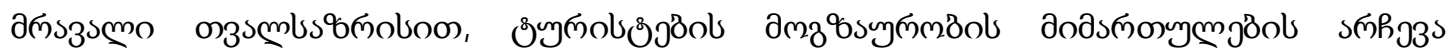

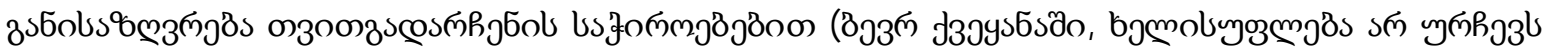

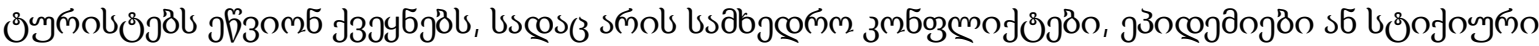

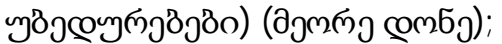

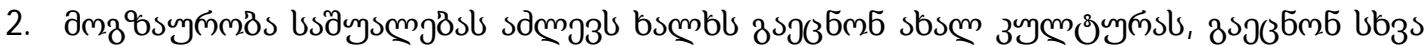

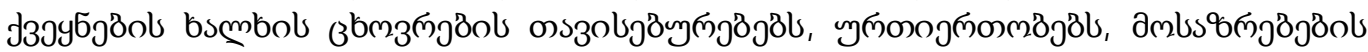

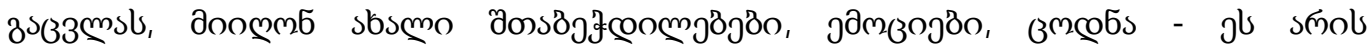

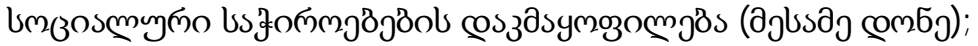

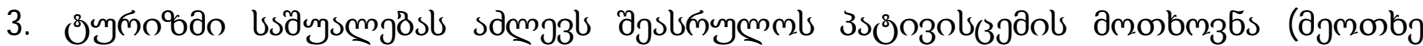

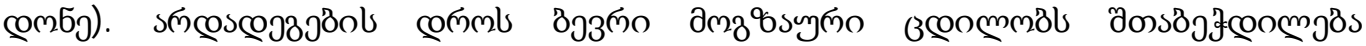

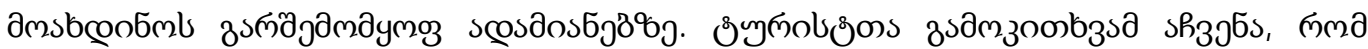

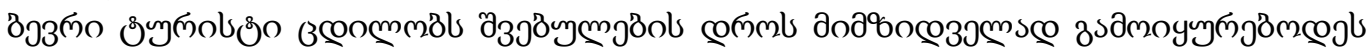

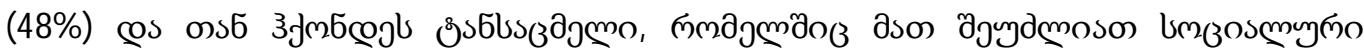

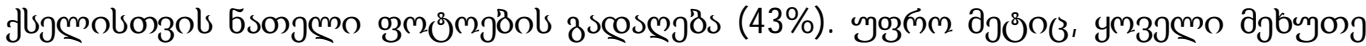

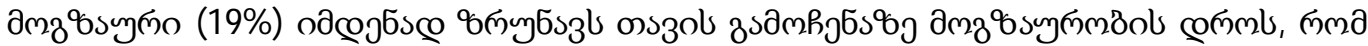

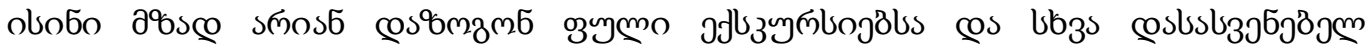

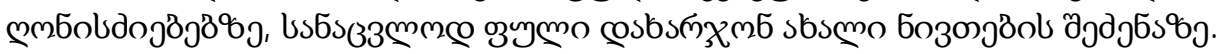

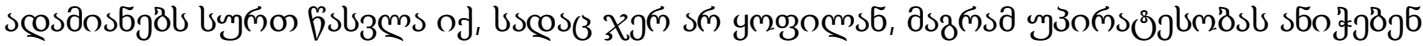

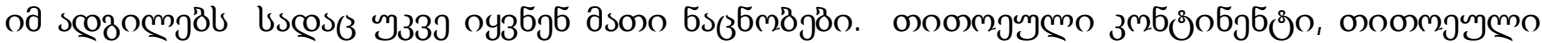

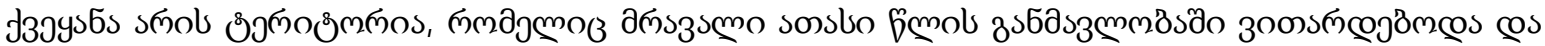

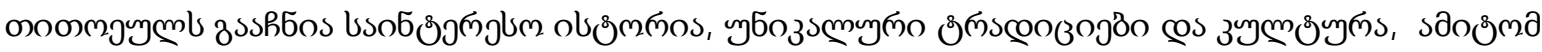

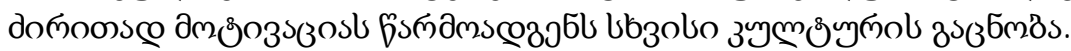

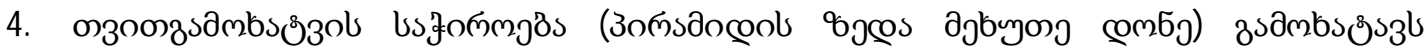

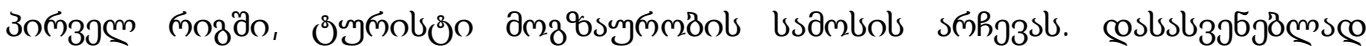

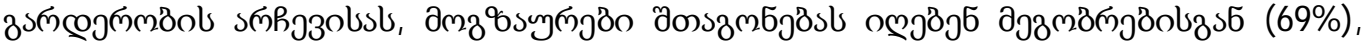

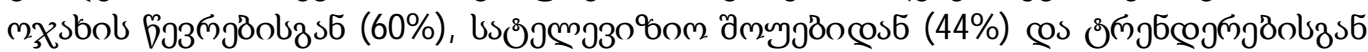

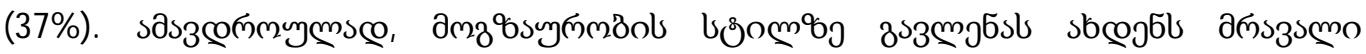

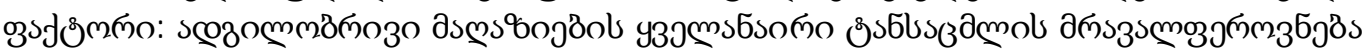

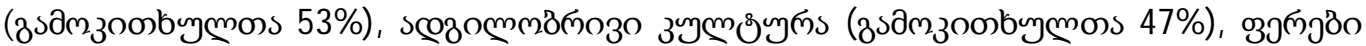

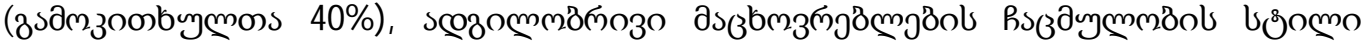

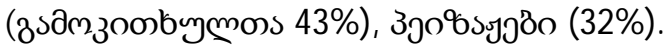

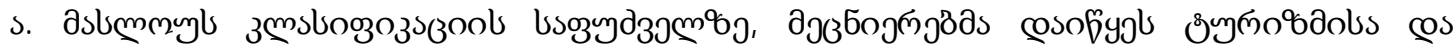

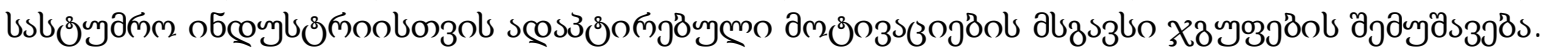

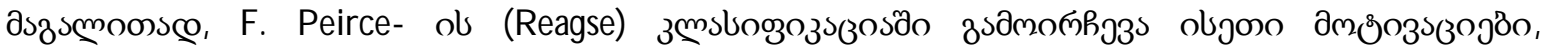

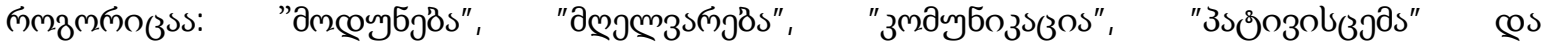

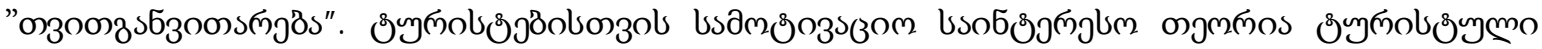

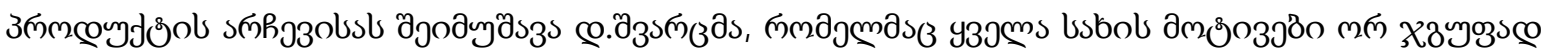

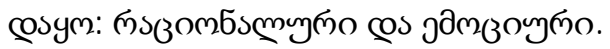

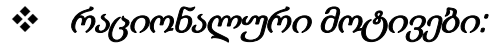

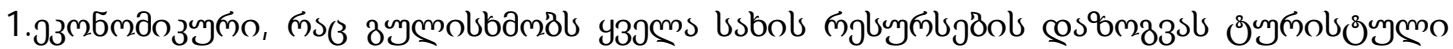

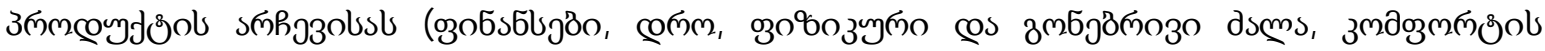

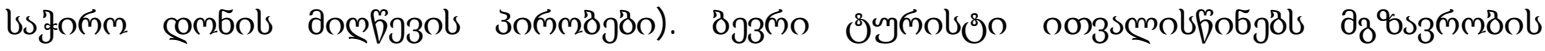

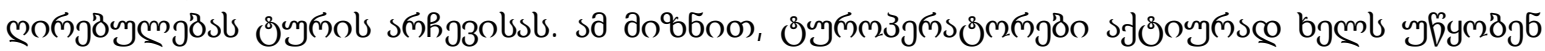

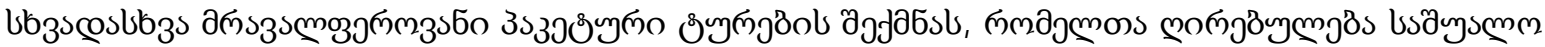

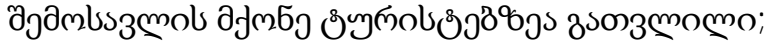




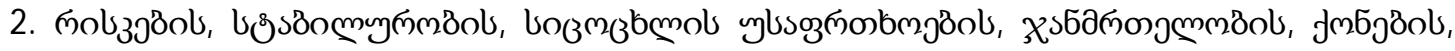

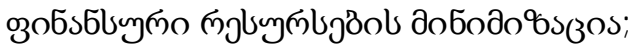

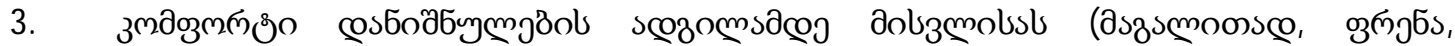

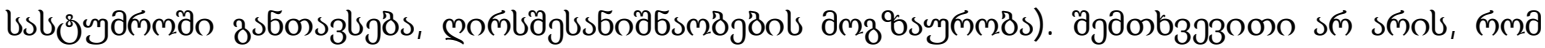

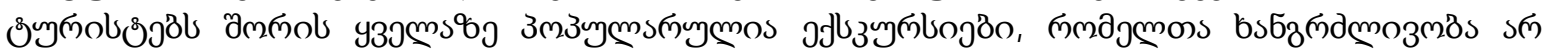

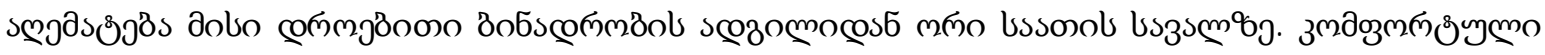

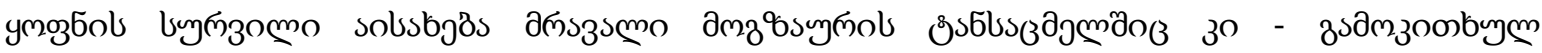

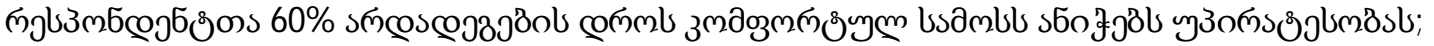

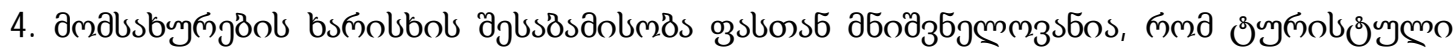

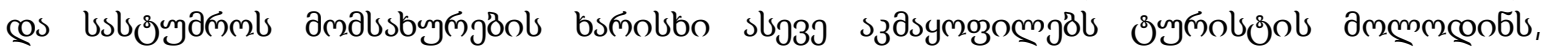

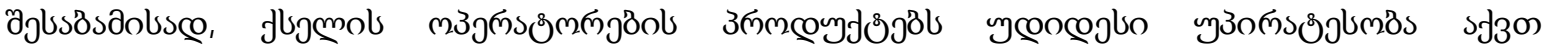

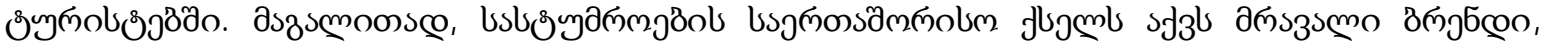

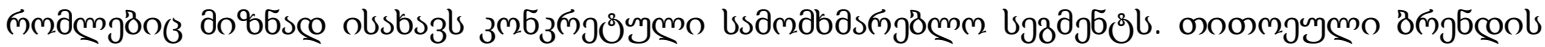

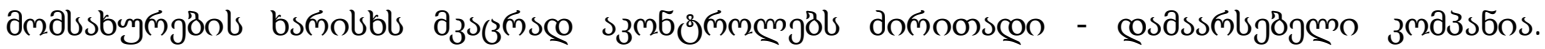

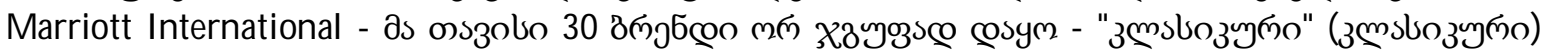

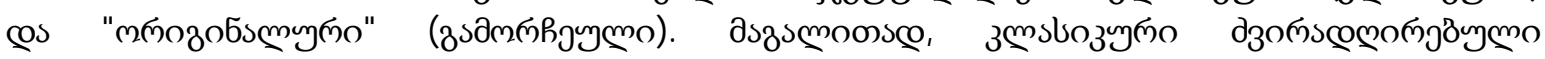

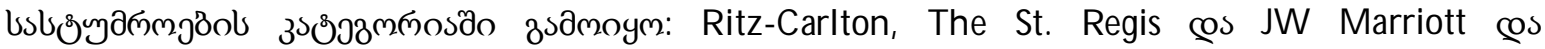

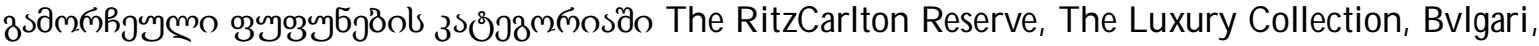

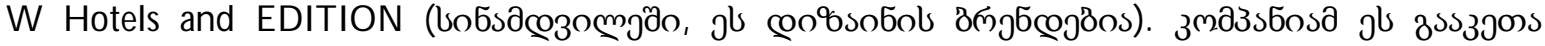

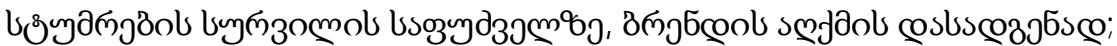

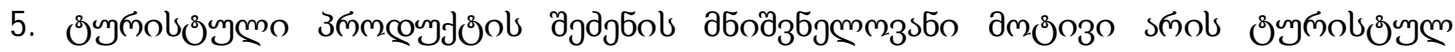

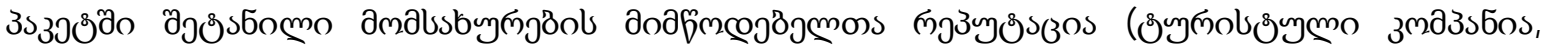

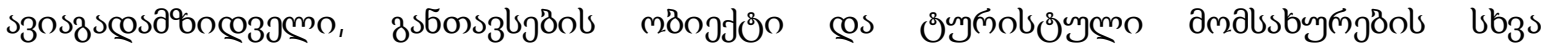

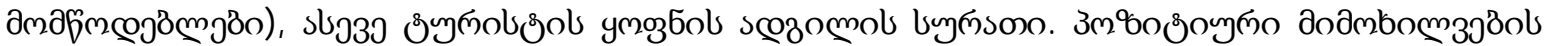

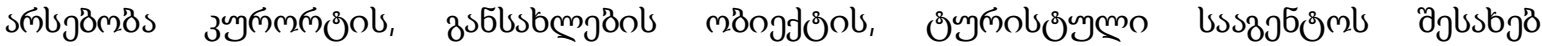

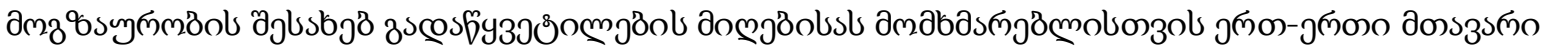

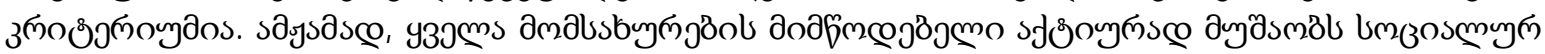

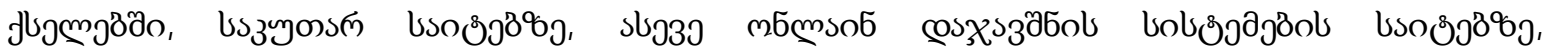

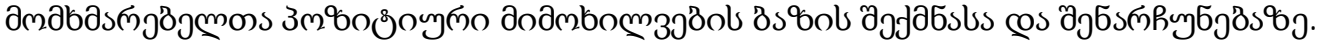

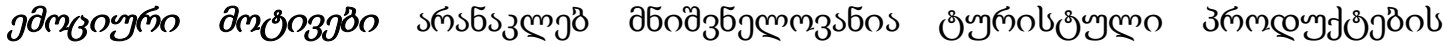

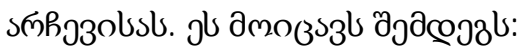

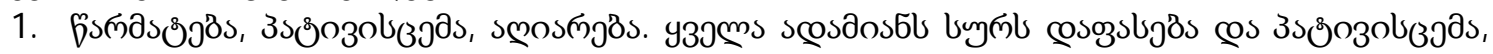

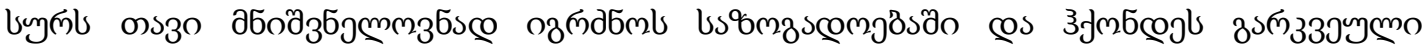
bơsơylo;

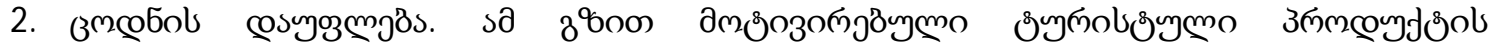

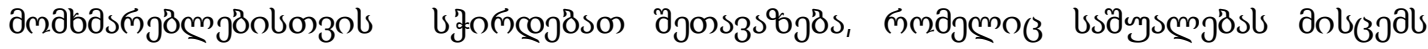

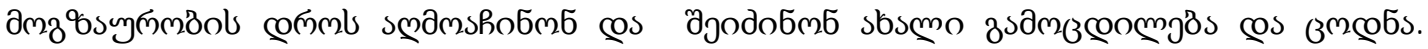

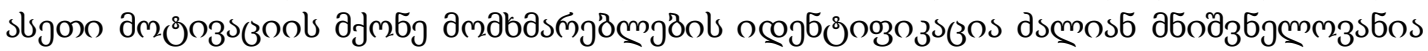

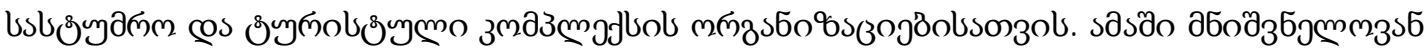

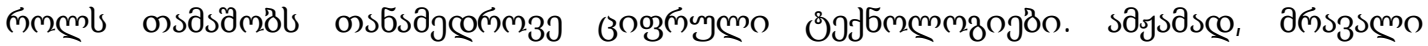

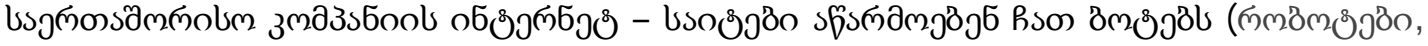

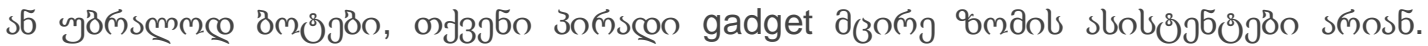

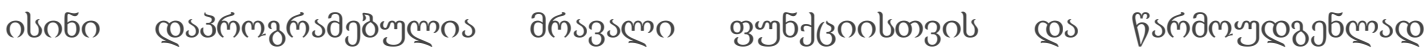

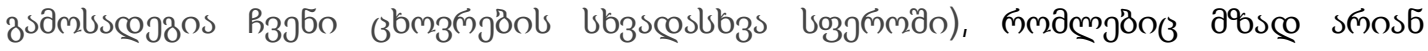

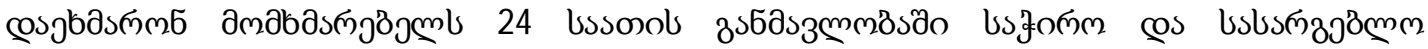

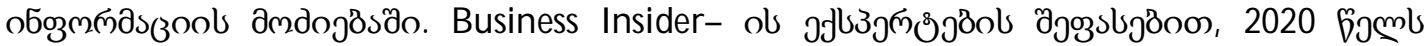

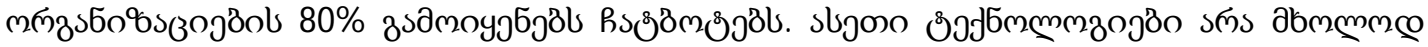

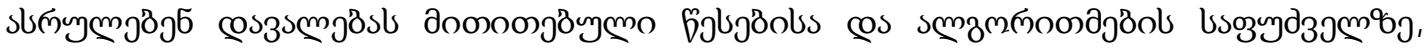

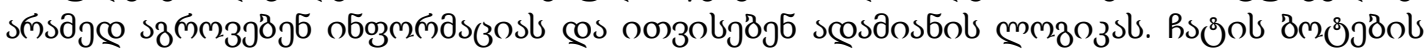

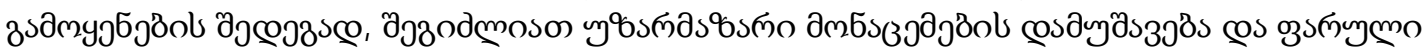




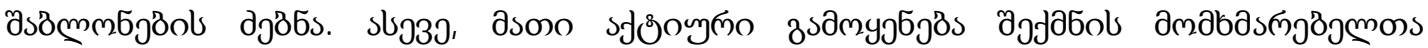

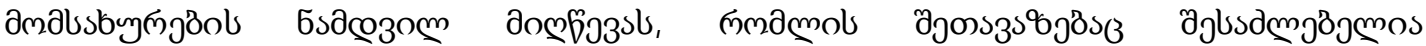

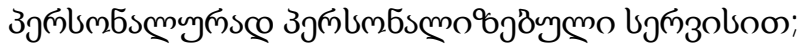

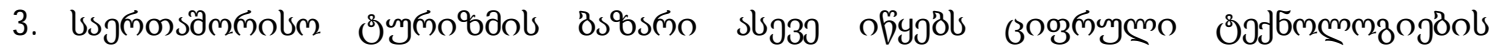

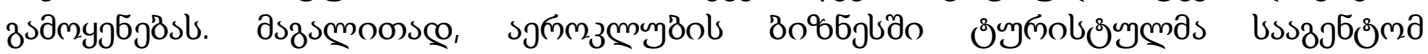

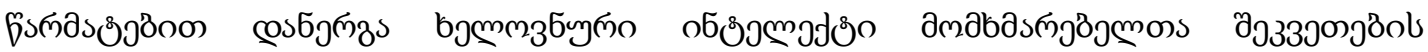

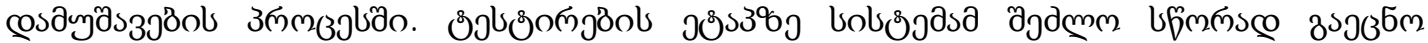

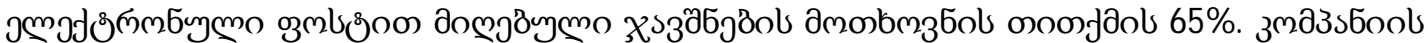

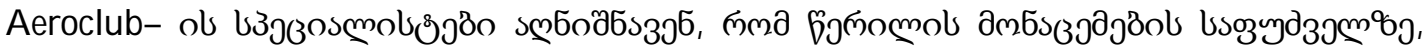

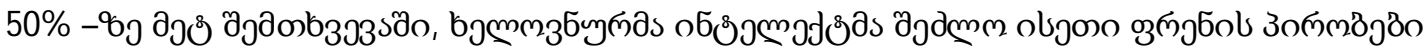

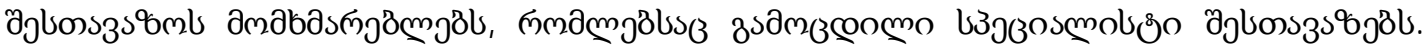

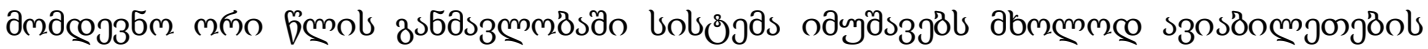

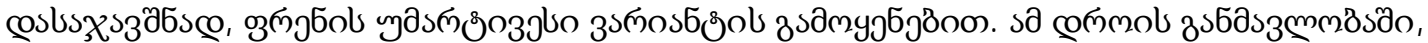

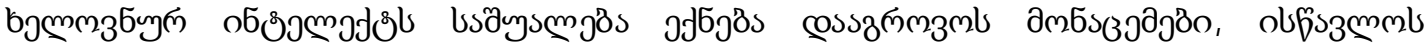

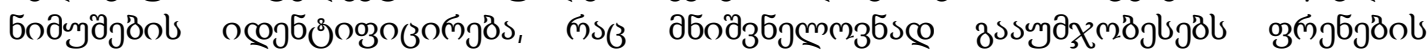

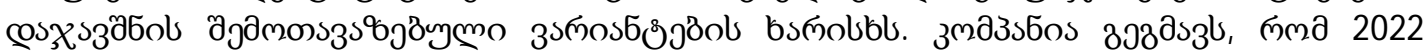

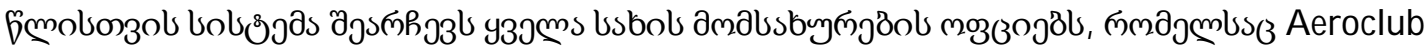

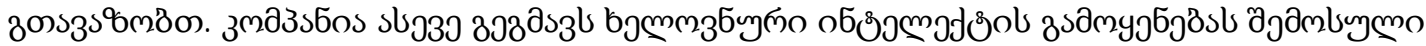
"osmjöol cosbsaỹaszjömsc;

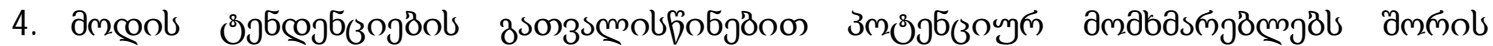

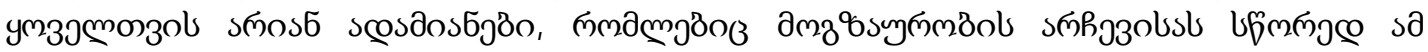

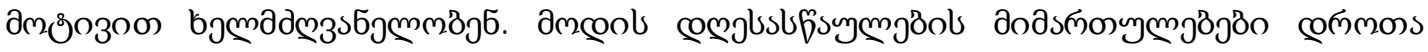

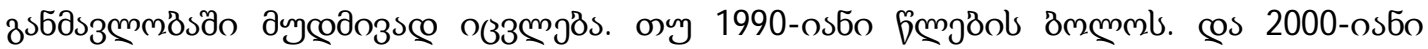

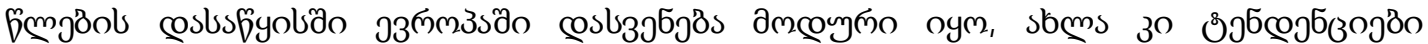

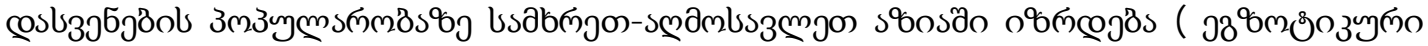

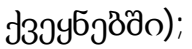

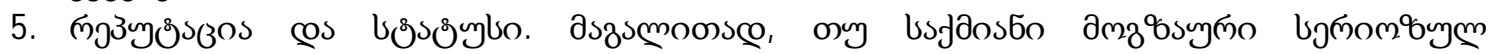

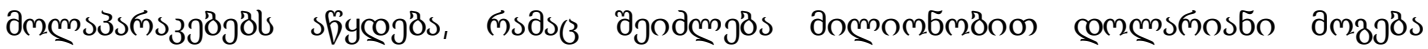

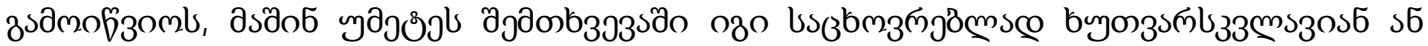

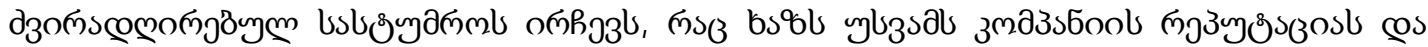

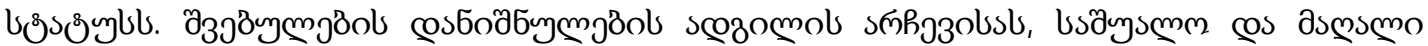
ஏృдmbsз

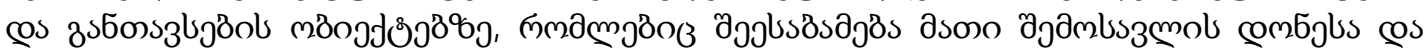

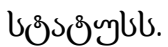

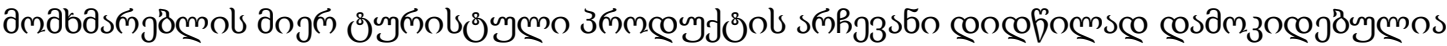

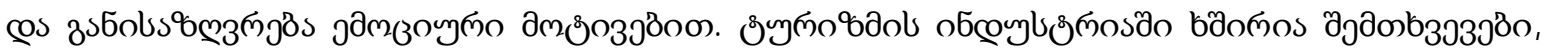

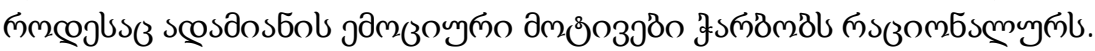

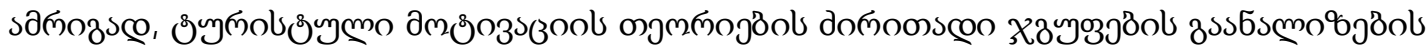

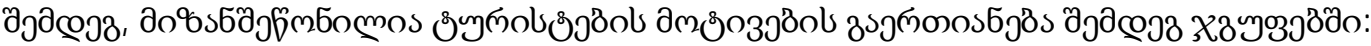

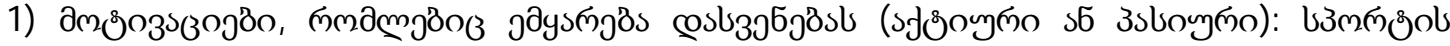

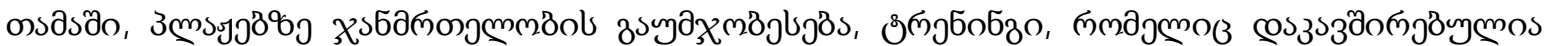

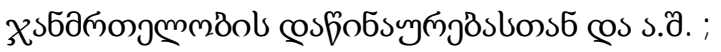

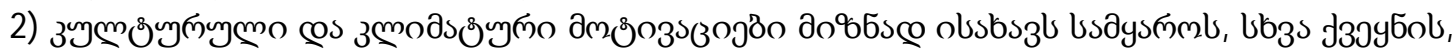

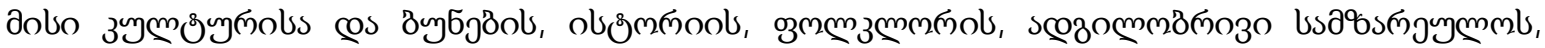

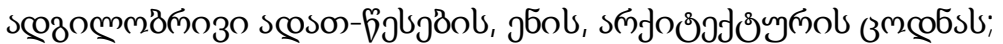

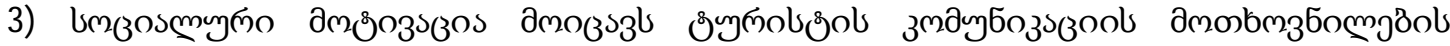

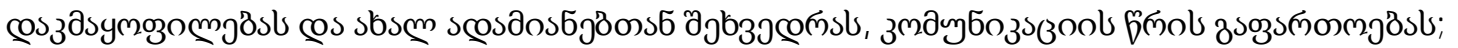

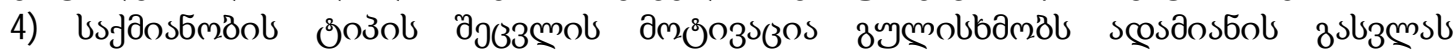

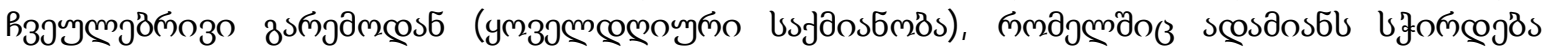

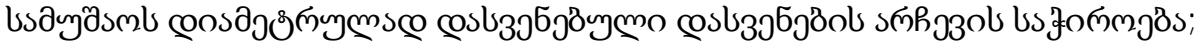




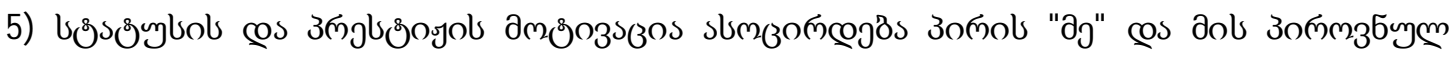

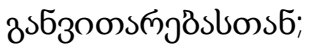

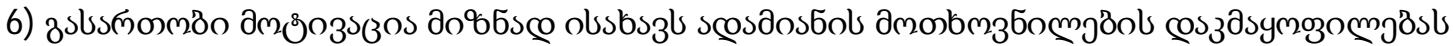

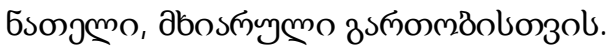

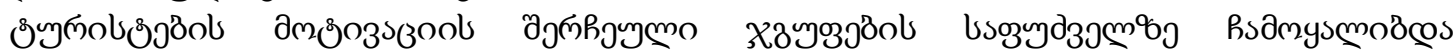

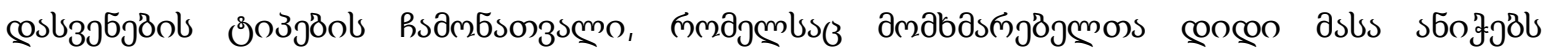
эзоп்

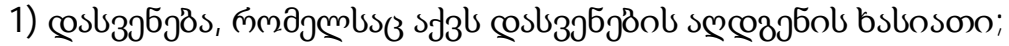

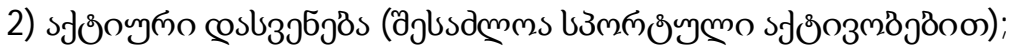

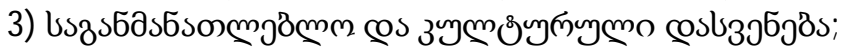

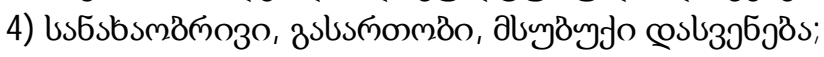

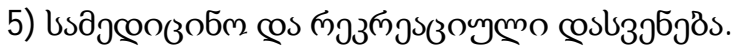

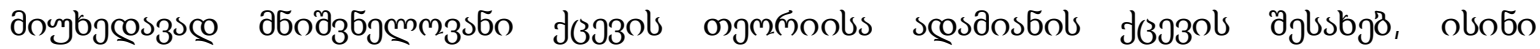

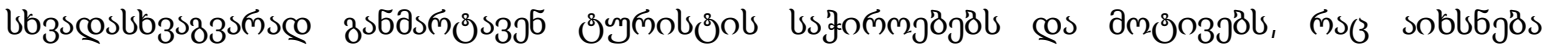

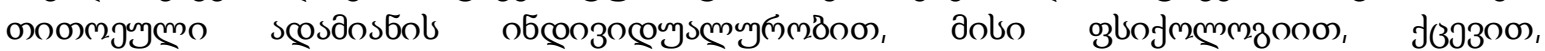
досп

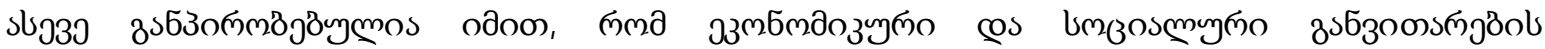

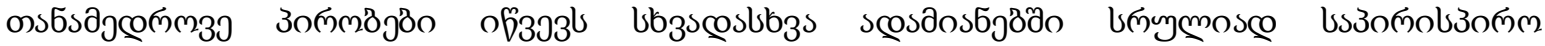

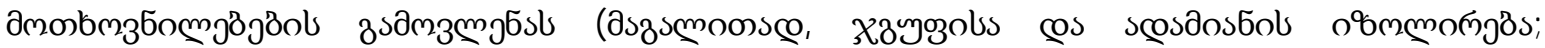

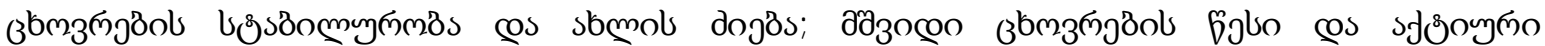

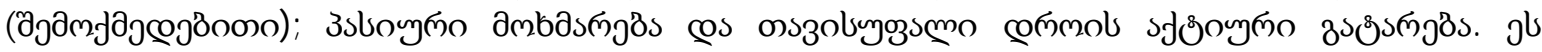

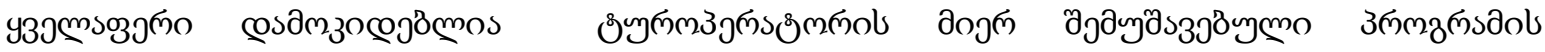

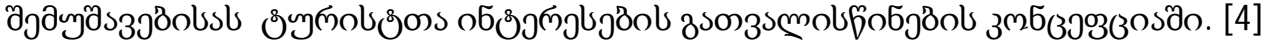

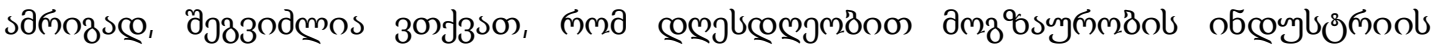

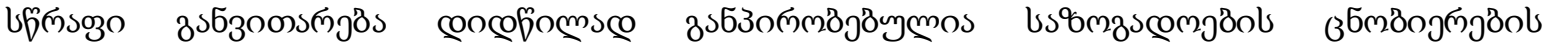

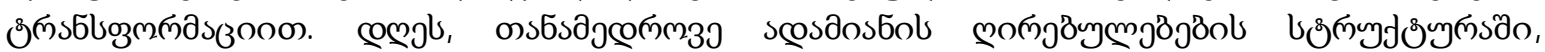

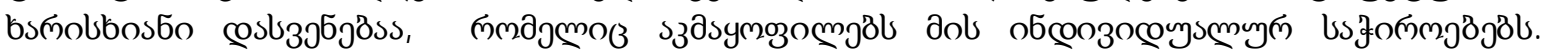

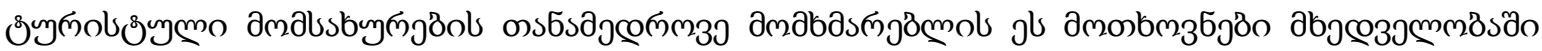

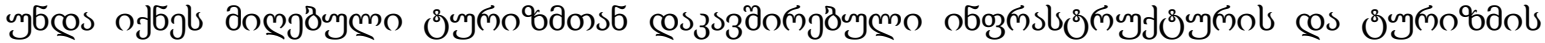

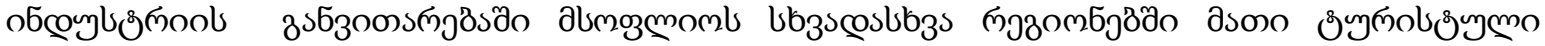

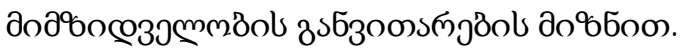

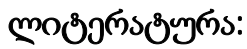

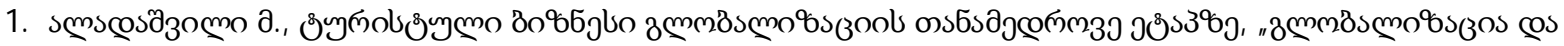
во\%бjlo" of

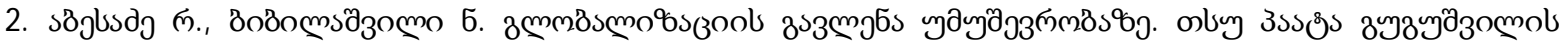

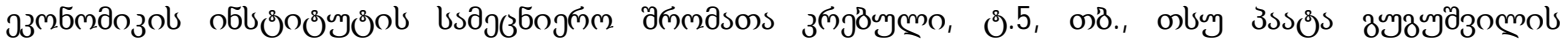

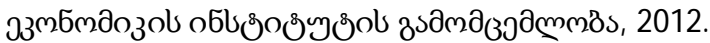

3. Andersson, T. D. (2007). The Tourist in the Experience Economy. Scandinavian Journal of Hospitality and Tourism, 7, 46-58.

4. Борисова А. О. Особенности и перспективы развития международного туризма // Экономические исследования. 2015. № 2. 


\title{
Managing the Motivation of Customers of International Tourism Services
}

\author{
Aladashvili Manana \\ Iakob Gogebashvili State University, Telavi
}

\begin{abstract}
The desires and needs of tourists are often considered to be the motivation for travel. The International Tourism Survey showed that there are four main factors: culture, destinations, social contact and adventure, which influence the decision of tourists to travel in international tourism.

The paper discusses the rational and emotional motives that influence tourists' travel choices and the selection of the tourism industry sector. Rational motives represent economic; Minimize risks, stability, life safety, health, property, financial resources; Comfort when arriving at the destination and compatibility of service quality with price.

Emotional motives are no less important, include knowledge acquisition, success, respect and recognition, consideration of fashion trends, reputation and status.

Based on the motivations of the consumers and the behavior of the people, a list of types of leisure has been formed, which is preferred by a large number of consumers:

1) rest, which has the character of restoration of rest;

2) active recreation (possibly with sports activities);

3) educational and cultural recreation;

4) Spectacular, entertaining, light rest;

5) Medical and recreational rest.

We can say that the rapid development of the travel industry today is largely due to the transformation of public consciousness. Today, in the structure of modern human values, there is a quality rest that meets his individual needs. These requirements of the modern consumer of tourism services should be taken into account in the development of tourism-related infrastructure and the tourism industry in order to develop their tourist attractiveness in different regions of the world.
\end{abstract}

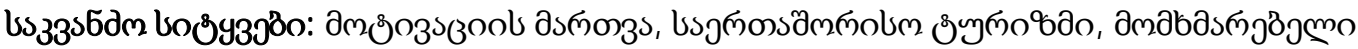

Keywords: Motivation Management, International Tourism, User 